\title{
Crave: uma análise do procedimento pós-dramático de Sarah Kane
}

\section{Lívia Sudare de Oliveira ${ }^{1}$}

\section{Resumo:}

Este artigo busca investigar o procedimento não dramático de Sarah Kane através da análise de seu texto Crave, buscando relacioná-lo às discussões recentes acerca do teatro pós-dramático, de forma a compreender que características lhe dão este aspecto. Visa-se com este trabalho, também, entender o que no trabalho de Kane fez com que passasse de enfant terrible do teatro inglês à melhor dramaturga (o) inglesa da década de 1990.

Plavras-chave: Sarah Kane, Crave, Pós-

Dramático, Dramaturgia Inglesa

\begin{abstract}
:
This paper investigates the post-dramatic procedures used by Sarah Kane on her work Crave, aiming to refer it to the recent debates concerning the post-dramatic theater, in order to identify the characteristics that give Kane's texts a post-dramatic aspect. It is also a purpose for this paper to spotlight which characteristics of Sara Kane's work made here go from enfant terrible to the best english female writer of the 1990's decade.
\end{abstract}

Key-words: Sarah Kane, Crave, Postdramatic, English dramaturgy

1 Doutoranda no Programa de Pós-Graduação em Teatro da Universidade Estadual de Santa Catarina. E-mail: lisudare@gmail.com 


\section{Introdução}

Na virada dos anos de 1990 a cena teatral inglesa passou a vivenciar mudanças na forma de se pensar o texto e o fazer teatral graças ao que Ahmet Biçer descreveu como "uma nova, jovem e brava geração cujo trabalho tem sido rotulado como provocativo, especulativo, confrontante, sensacional, chocante, que quebrou tabus; brutal, gélido, tenebroso e sombrio " " (BIÇER, 2011, p.75). O teatro experimental feito por esses jovens autores logo ganhou a alcunha de "in-yer-face theatre ${ }^{2}$ " e levou para o país algumas discussões acerca de uma estética de ruptura que não possuísse como centro o texto dramático.

Hoje a teoria conseguiu elencar diversos tópicos relacionados a essa estética de ruptura, tais como a quebra no modelo hegemônico do drama (BAUMGARTEL, 2009), a crise da representação (POSCHMANN, 1997), a incerteza do personagem e a emancipação do diálogo em relação ao seu enunciador (SERMON, 2005), a "mudança do hermenêutico para o não hermenêutico, do semiótico para o performativo" (FISCHER-LICHTE, 2001, p.230). Enfim questões que, há alguns anos, já permeavam debates no campo dos estudos teatrais - tanto na teoria quanto na prática - em países como Alemanha e França.

A partir de tais estudos, chegou-se a um estágio no qual o texto teatral não precisa mais ser associado ao texto literário. Gerda Poschmann afirma, em relação à cisão entre os gêneros, que.

a "separação do teatro da literatura" pode ser denominado o "fato fundador da modernidade teatral", pois a dominância do conceitual-simbólico (da 'compreensão mental') sobre o visual-icônico (a 'percepção sensorial') na cultura ocidental foi minada por um ceticismo linguístico e uma renascença do elemento visual. (POSCHMANN, 1997, p.2)

A autora pontua então que com essa separação acontece a "teatralização do teatro". Theresia Birkenhauer (BIRKENHAUER, 2007) postula que não se pode mais falar em texto "inapto para o palco", visto que características de forma ou gênero não são mais um empecilho para colocar um texto no universo teatral. As fronteiras formais foram diluídas. Como bem aponta Hans-Thies Lehmann (LEHMANN, 2004, p.26) o "conceito de texto dinamizou-se" e assim o foco principal passa de sua forma acabada para o seu processo de feitura, "a 'escrita' com seu caráter fundamentalmente aberto, inacabado e polissêmico: o 'geno-texto' que se encontra sob o 'fenotexto', o ritmo do 'semiótico' debaixo do 'simbólico'" (LEHMANN, 2004, p.26). Lehmann entende que a ampliação do conceito de texto revaloriza a fala como ato performativo.

Inserida em meio aos debates acerca de procedimentos teatrais não dramáticos ou pósdramáticos, está a curta carreira da autora britânica Sarah Kane. Nascida em 1971, Kane deixou apenas cinco peças escritas antes de cometer suicídio em 1999. A sua curta obra é, no entanto, um retrato de experimentações que envolvem o texto teatral sendo abordado de uma forma não convencional para os padrões do teatro britânico da época.

Este artigo tem por objetivo fazer uma análise do texto Crave da autora Sarah Kane, buscando relacioná-lo às discussões recentes acerca do teatro pós-dramático, de forma a compreender que características lhe dão este aspecto. Visa-se com este trabalho, também, entender o que no trabalho

\footnotetext{
1 "new angry young generation whose works have been labelled provocative, speculative, confrontational, sensational, shocking, taboo-breaking, brutal, bleak, gloomy and dark."

2 Em tradução livre: "teatro jogado na sua cara", dada a característica violenta e o fato de buscar chocar a audiência.
} 
de Kane fez com que passasse de enfant terrible do teatro inglês à melhor dramaturga (o) inglesa da década de $1990^{3}$.

\section{Crave como expressão do teatro pós-dramático de Sarah Kane}

Sarah Kane não foi a representante solitária de um movimento isolado. O teatro não dramático foi levado para os palcos ingleses, não só por ela, mas também por autores como Mark Ravenhill, Anthony Neilson, Martin McDonagh, Joe Penhall, Jez Butterworth e Judy Upton. Estes jovens viriam a ser apontados pela imprensa inglesa, de acordo com Ken Urban (URBAN, 2001, p.37), como os "Novo Niilistas Ingleses" e ou "Novos Brutalistas".

Post mortem, Sarah Kane é apontada pela crítica como um dos grandes nomes da dramaturgia britânica, porém, a recepção inicial ao seu trabalho no Reino Unido não foi calorosa. De fato, quando estreou seu primeiro trabalho, Blasted, em janeiro de 1995 no Royal Court Theatre em Londres, Kane foi recebida com ojeriza pela crítica. Segundo Ian Ward (WARD, 2013, p.225), um crítico definiu aquele espetáculo como "um nojento banquete de obscenidades ${ }^{4}$ ", enquanto outro concluiu que a peça não "precisava de um crítico de teatro, e sim de um psiquiatra ". A postura da crítica em seu país não suavizou muito em relação aos espetáculos seguintes. Convém ressaltar, entretanto, que o trabalho de Sarah Kane foi muito bem recebido em outros países europeus.

Sarah Kane chocou a crítica teatral em seu país não só por suas escolhas de ruptura na forma, mas também, pelas temáticas abordadas em suas peças. Seu trabalho está permeado por questões relativas à morte, violência, estupro, dor, melancolia, ânsia sexual, ansiedade e ainda segundo Biçer pelas "dimensões físicas e psicológicas da crueldade" (BIÇER, 2011, p.76). Como aponta Ward (WARD, 2013) a base dos escritos de Sarah Kane está centrada na sexualidade e na violência e quando a sua intenção é intensificar esta violência, ela faz uso repetido do estupro. Segundo Cristina Delgado Garcia, o foco da temática de Kane está na "exploração dos limites da experiência humana" (GARCIA, 2012, p.230).

Sarah Kane construiu em Crave um texto altamente linguístico e complexo, que recorre a diversos recursos verbais e imagéticos na tessitura de sua estrutura. A palavra é o centro desta obra, que não busca criar uma narrativa com começo, meio e fim, mas percorrer labirintos linguísticos e se deixar levar por diálogos que na verdade são experimentações com a língua. Dentre os mecanismos de escrita utilizados por Kane está à repetição de palavras, utilização de outros idiomas, a citação de passagens de obras de outros autores e o eventual uso da rima.

A autora buscou nova forma de presentificar no palco a condição humana. Crave é um texto que não pode ser descrito através do que Stephan Baumgartel chamou da "criação de sua fábula, ou seja, através de uma análise da construção da sua narrativa ficcional que leva em conta as suas dimensões temáticas" (BAUMGARTEL, 2009, p.127). Não pode, pois não há uma fábula ou uma narrativa ficcional que o conduza claramente.

Inseridos neste universo da fala estão quatro personagens incertos, anônimos, locados em um espaço não definido. Eles não são o que Fischer-Lichte (FISCHER-LICHTE, 2001) chama de

3 Graham Saunders em sua obra Love me or kill me: Sarah Kane and the Theatre of Extremes, afirma que Sarah Kane "é considerada a maior dramaturga inglesa da década de 1990, definitivamente a mais radical" (2002, p.134)

$4 \quad$ "a disgusting feast of filth"

$5 \quad$ "it's not a theatre critic that's required, it's a psychiatrist." 
dramatis personae, visto que não possuem nome, seus gêneros não são postos de antemão e não há nenhuma característica anterior que os defina. Birkenhauer (BIRKENHAUER, 2007) aponta que com as propostas terminológicas para substituir o drama, também vieram propostas para substituir o conceito de personagem. Segundo ela é sugerido "falar antes em "portadores de texto", "instâncias de discursos" ou "instâncias locucionais"." (BIRKENHAUER, 2007, p.1). No entanto, parece que o nome que se dá a coisa é de fato menos importante do que a coisa em si.

Assim, os "portadores de texto" ou personagens de Crave não comandam o que falam. Enunciam palavras que não necessariamente são parte de suas fábulas, porque nesta obra que importa não é a construção de uma narrativa, mas sim o próprio encadeamento de palavras e a sua expressão sonora. Os quatro personagens falam de acontecimentos que fazem referencia aos outros, no entanto, suas interações não se dão de maneira direta.

As identidades destas figuras não são estáveis. Após algumas leituras do texto de Kane, é possível chegar perto de uma conclusão: C e M são mulheres, C é uma jovem que sofreu violência sexual por parte do avô e M é uma mulher de meia idade que quer ter um filho, A e B são homens, sendo que A é o avô de C e um pedófilo declarado, B por sua vez, é um jovem que está apaixonado por $\mathrm{M}$. Tanto $\mathrm{C}$ quanto $\mathrm{B}$ transferem para $\mathrm{M}$ a figura materna. E o A vive a culpa de amar a própria neta. Sarah Kane em entrevista a Dan Rabellato deu indícios sobre no que consistia essas instâncias do discurso.

Para mim A sempre foi um homem mais velho, $\mathrm{M}$ sempre foi uma mulher mais velha, assim como B sempre foi um homem jovem e C uma mulher. A,B,C e M possuem significados específicos, os quais estou preparada para lhe contar. A é muitas coisas: o autor e o abusador, porque de fato são as mesmas coisas; Aleister como em Aleister Crowley, que escreveu alguns livros interessantes que você pode vir a gostar de ler, e o Anti-Cristo. Meu irmão trouxe a ideia de arse-hole, o que eu considerei bom. Tem também o ator para quem eu escrevi originalmente o personagem, que se chamava Andrew, então foi assim que A tomou vida. M era simplesmente de mãe, $B$ era um garoto (boy em inglês) e C era de criança. Mas eu não queria escrever estas coisas, porque depois eu pensei que isso os fixaria nestas coisas para sempre e eles nunca mudariam. (Rabellato apud Biçer, 2011, p.86)

Crave trata da história do passado desses quatro portadores de texto, de seus anseios e seus problemas. É menos uma história de violência crua do que é uma história de amores disfuncionais e anseios frustrados. Os personagens irrompem muitas vezes como vozes solitárias, proferindo monólogos que podem ou não ter relação com os outros. Ousmane Ale Pame aponta que

Apesar dos pensamentos dos personagens em alguns momentos estarem relacionados, eles não necessariamente respondem uns aos outros. Cada voz é pessoal e profundamente imersa em uma solidão depressiva como que relacionando os acontecimentos de uma vida triste e cheia de incidentes traumáticos. (PAME, 1998,p.7)

A questão da solidão está relacionada à questão do "personagem incerto", sem identidade estável. Florence Baillet aponta que 


\section{Lívia Sudare de Oliveira}

os outros, seria como prisioneiro de seu universo, fechado dentro de sua solidão e de seu discurso, o qual teria mais relação com o monólogo do que com o diálogo [...] o personagem também já não constitui um espaço de identidade estável, mas se mostra aberto a todo tipo de vento. (BAILLET, 2005, p.26)

A repetição de ideias, sons e imagens nos monólogos dos portadores de texto leva, em determinados momentos à formação de um só ser. Isto pode ser exemplificado ${ }^{6}$ em diversas passagens em que as curtas falas dos personagens parecem ser na verdade a fala de uma só, como na passagem em que A pergunta: “What do you want?", em seguida C profere: “To die", B continua: "To sleep" e M finaliza: "No more" " (KANE, 2000, p.7). Com estas três falas fragmentadas Sarah Kane faz alusão ao célebre monólogo de Hamlet, o que evidencia a questão de que em certos momentos os portadores do texto parecem se juntar em um só ser proferindo um monólogo.

A repetição segundo Ruby Cohn (COHN, 2008, p.7) é utilizada em determinados momentos para conferir stress. Indo além, talvez seja possível afirmar que a repetição é utilizada em diversos momentos para exprimir stress. M é uma mulher sob a pressão da idade que deseja ser mãe, em uma passagem B lhe diz: "You could be my mother", ela parece lhe responder: "I'm not your mother", então A simplesmente fala: "Baby", em seguida M irrompe em uma sequência de repetição: "now now now now now now now ${ }^{8}$ (KANE, 2000, p.17). Após um monólogo enorme no qual A declara o seu amor, um amor obsessivo, C, que é sua neta e carrega a lembrança do estupro lhe infligido por ele, entra em uma série de repetição: “C: (Under her breath until A stops speaking.) this has to stop this has to stop this has to stop this has to stop this has to stop this has to stop this has to stop this has to stop (Then at normal volume) this has to stop this has to stop this has to stop ${ }^{\text {" }}$ (KANE, 2000,

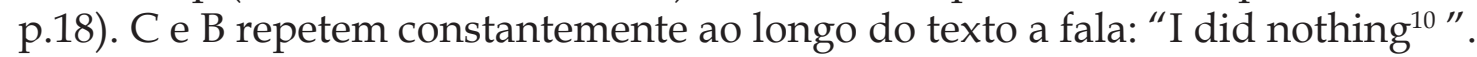

Outro recurso verbal utilizado pela autora é a contradição. As formas mais evidentes de contradição são as sequências ritmadas de falas "sim" e "não". Há ainda passagens de falas curtas que também evidenciam a contradição. Em uma dessas passagens C fala: "Leave”, A diz: "Come back" e todos juntos proferem: "Stay" " (KANE, 2000, p.8). Outro exemplo é quando C diz: "I don't want to stay", B repete a mesma fala, então C finaliza: “I want you to leave” (KANE, 2000, p.14). Outro exemplo é "C: Someone has died who is not dead" " (KANE, 2000, p.16).

Há falas que são apenas verbos que indicam ação, tem diversas passagens que os portadores do texto falam: "Look" e "Listen"13 (KANE, 2000, p.18). Em outro ponto M diz: "Express it", B continua com: "Explain it" e A finaliza com: "Maintain it 14" (KANE, 2000, p.23). Outras falas são verbos que indicam que o sujeito sofreu a ação: “M: Beaten, A: Broken 15” (KANE, 2000, p.26). Sarah Kane também faz uso de rimas seja entre palavras de um única fala “A: Because love by its nature

6 Os fragmentos do texto são aqui citados na sua língua original, para evidenciar melhor alguns dos procedimentos escolhidos pela autora.

7 "A: O que você quer? C: Morrer, B: Dormir, M: Nada mais."

8 "B: Você poderia ser minha mãe. M: eu não sou sua mãe. A: baby. M: agora agora agora agora agora agora agora."

9 "C (sussurrando até que A pare de falar) isso tem que parar isso tem que parar isso tem que parar isso tem que parar isso tem que parar isso tem que parar isso tem que parar isso tem que parar isso tem que parar isso tem que parar (Depois em um volume normal) isso tem que parar isso tem que parar isso tem que parar."

10 "Eu não fiz nada".

11 "C: Vá embora. A: Volte. Todos: Fique."

12 "C: Alguém morreu que não está morto".

13 "Olhe" e "Escute".

14 "Expresse-o". "Explique-o". "Mantenha-o"

15 "M: espancada". "A: quebrado". 
desires a future ${ }^{16 "}$ (KANE, 2000, p.6), seja entre falas: “A: I am not what I am, I am what I do. M: This is terrible. C: This is true $\mathrm{e}^{17 "}$ (KANE, 2000, p. 27).

Sarah Kane também utiliza o mecanismo da citação literária em Crave. Como já foi mencionado acima, frases do monólogo de Hamlet são citadas por Kane. Ruby Cohn (COHN, 2008, p.7) ressalta que as falas "Let the day perish in which I was born / Let the blackness of the night terrify it / Let the stars of its dawn be dark / May it not see the eyelids of the morning / Because it did not shut the door of my mother's womb ${ }^{18}$ " (KANE, 2000, p.36), são, na verdade, passagens do Livro Jó sem as pontuações que constam na publicação bíblica. Cohn ainda menciona que pelo menos quatro falas, faladas por M e B, foram retiradas da obra Wasteland de Thomas Stearns Eliot. Há ainda falas em línguas estrangeiras como espanhol, alemão e sérvio.

Crave é um texto dotado de heterogeneidade. Esta característica vem lhe conferir um aspecto crítico, visto que, através das brechas que a heterogeneidade confere ao diálogo, é possível ver questões fragmentadas da própria sociedade, conforme Florence Baillet percebe

A heterogeneidade do diálogo testemunha agora uma linguagem não autêntica; o chamado "sujeito" falante [locutor] é como que possuído por outras vozes que não sejam a sua. E o autor dramático pode se entregar a uma análise (crítica) da sociedade por meio desses "personagens" (se podemos ainda arriscar o emprego desse termo), que sofrem a influência de discursos dominantes sem serem capazes de articular sua própria situação usando suas próprias palavras. Portanto, são ressaltados o impacto do poder sobre os indivíduos e a petrificação das clivagens no seio da sociedade. A dimensão política desses textos não reside, portanto, em sua dimensão vidente ou demonstrativa, mas vem se alojar nas falhas do diálogo. (BAILLET, 2005, p.27)

O trabalho de Sarah Kane trata de uma série de aspectos cruciais característicos da vida pósmoderna. Através de seu texto não narrativo, Kane almeja que o público vivencie questões como a violência sexual, a solidão, a dor, a perda de identidade, a vontade de morrer, o amor obsessivo, o desejo sexual, e não que veja esses tópicos através de uma representação distante. As falhas do diálogo forçam o individuo a sair da zona de conforto. Ahmet Biçer fala sobre a violência na obra de Kane:

A maioria de seus personagens são vitimas de crueldade e de agressão, o que caracteriza a vida pós-moderna. [...] Ela utiliza a violência como uma tática de choque para inspirar seu público a não assistir passivamente, e sim tomar uma ação contra as atrocidades da vida. (2011, p.2).

Crave é um texto crítico, mas em que estão seria político? Para Hans-Thies Lehmann “o teatro é político onde ele realiza um abalo da moralização ligada à personalização. Desmontagem ou desconstrução dos simulacros políticos no teatro quer dizer: evitar as armadilhas moralistas" (LEHMAN, 2001, p.10). Ao tratar das dimensões verbais da violência, Kane não as moraliza, as apresenta inesperadamente de forma poética e musical. Uma postura moralista jamais permitiria um monólogo na qual um pedófilo declara seu amor à neta a quem violentara na infância. Crave traz, nas palavras de Ruby Cohn, "a desintegração da mente humana sob as pressões do amor,

16 "A: Porque o amor por conta de sua natureza anseia pelo futuro".

17 "A: Eu não sou quem eu sou, seu sou o que eu faço. M: Isso é horrível. C: Isso é verdade".

18 "Deixe o dia em que nasci perecer/ Deixe a escuridão da noite aterrorizá-lo/ Deixe as estrelas do seu amanhecer escurecerem/ Que ele não veja as pálpebras da manhã/ Porque ele não fechou a porta do útero de minha mãe." 
perda e desejo." (COHN, 2001,p.5). Entretanto, Kane não traz soluções para essa desintegração, ela a presentifica em todas as suas formas.

Ao analisar Crave é possível compreender que o teatro de Sarah Kane é um teatro de experimentação, investigação. Kane se afasta do realismo ao expor a hiper-realidade das emoções e interações humanas. Ela não busca representar a violência, a dor, o desejo, a vontade de morrer e o amor obsessivo, mas sim presentificá-los. Nesse sentido, não é possível deixar de citar a crise da representação observada por Gerda Poschmann, segundo a qual "não cabe mais à arte, como se fosse ainda uma arte de objetos representacionais, a tarefa de mediar ("vermitteln") entre forma e conteúdo" (PORSCHMANN, 1997, p.4 ). Crave se encaixa ainda na descrição de Porschmann acerca do novo status do texto: novo status do texto se reflete também no teatro: "a utilização do texto enquanto material já aparece na característica textual de ser uma colagem de fragmentos e citações, mas também no seu uso enquanto "sound pattern" e "estrutura rítmica de signficantes"."(1997, p.11).

Kane se utiliza de citações e fragmentos, em seu texto várias falas são conectadas por tempos. Como bem aponta Juliana Pamplona (PAMPLONA, 2009, p.8) “As personagens de Crave funcionam dentro de um jogo de linguagem em que as palavras faladas e seus ritmos, entonações e intenções são seu principal veículo." Um exemplo é a passagem rítmica abaixo:

A beat.

B No.

C No.

M Yes.

B No.

C No.

A Yes.

C No

A beat. (KANE, 2000, p.33)

\section{Conclusão}

Crave, texto escrito um ano antes do suicídio de Sarah Kane, é um experimento com a forma textual. O texto é permeado por diálogos fragmentados que não necessariamente possuem relação entre si. Esta postura adotada por Kane pode ser entendida como um espelhamento das desconexões da vida pós-moderna. O texto não possui indicações de tempo ou de espaço, ou narrativa cronológica.

Ela rompe com o teatro dramático ao criar personagens não dramáticos, sem caracterização, que não possuem nenhuma informação que os defina além de letras alfabéticas. Sarah Kane criou personagens incertos. A interação dos portadores do texto não exemplifica uma narrativa concreta. Há uma desindividualização do indivíduo nessa obra, visto que o ato da fala não serve como em muitos casos, para expressão individualizada de um ser. Diversas vezes os personagens fundem-se 
em monólogos, caracterizando um ser único. A individualização do ser aparece quando é retratada a questão da solidão. Então um personagem de Crave é ao mesmo tempo um e outro maior.

Diferente de em seus outros textos, a violência contida no texto não é presentificada através de atos físicos em cena, mas através das memórias fragmentadas dos personagens, visto que Crave é altamente linguístico. Ao invés de apresentar corpos desmembrados, Kane apresenta psychés desmembradas. Mas o faz de maneira poética, ritmada e sonora.

Ao longo deste artigo foram apontados aspectos de Crave que possibilitam que a obra seja considerada um texto não dramático. São alguns desses aspectos: personagens incertos, estrutura fragmentada do texto, tempo e espaço não delimitado, citação de obras literárias, narrativa não linear, uso de falas em língua estrangeira, presentificação ao invés de representação, repetição de palavras, uso de rima, dentre outros. Todos estes recursos são usados por Sarah Kane para desafiar o público, para tirá-los da apatia e faze-los lutar contra as atrocidades da vida. Viu-se também que a forma como Kane aborda as temáticas de Crave pode ser entendida como política.

Sarah Kane ainda continua sendo um nome controverso no teatro britânico. Alguns críticos dão crédito à sua genialidade por seu trabalho, outros dão crédito a depressão por peças com temáticas tão obscuras, chegando a considerar a sua última peça Psychosis 4.48 um bilhete suicida. De qualquer forma, Kane veio romper com velhas convenções do teatro inglês, deixando como legado o seu teatro experimental, influenciando novos artistas a buscarem perspectivas diferentes para se pensar o teatro.

\section{Referências}

BAILLET, Florence. A Heterogeneidade. Tradução Stephan Baumgärtel e José Ronaldo Faleiro. Publicado sob o título "L'Héterogénéité" em: Ryngaert, Jean-Pierre et al. Nouveaux Territoires du Dialogue. ActesSudPapiers/CNSAD 2005, p.26-30.

BAUMGARTEL, Stephan. Em busca de uma teatralidade textual performativa além da representação dramática in Sobre Performatividade. Org. Edélcio Mostaço, Isabel Orofino, Stephan Baumgartel e Vera Collaço. Santa Caratina: Letras Contemporâneas, 2009. p. 127-179.

BIÇER, Ahmet Gökhan. Depiction of violence on stage: physical, sexual and verbal dimensions of violence in Sarah Kane's experiential theatre. The Journal of International Social Research. Volume: 4. Issue: 16. Winter 2011. p.81-88

. Sarah Kane's postdramatic strategies in Blasted, Cleansed and Crave. The Journal of International Social Research. Volume: 4. Issue: 17. Spring 2011.

BIRKENHAUER, Theresa. "O tempo do texto no teatro“. Trad. Stephan Baumgärtel, não publicada. Original em: TIGGES, Stefan (ed). Dramatische Transformationen. Zu gegenwärtigen Schreib- und Aufführungsstrategien im deutschsprachigen Theater. Bielefeld: Transcript, 2008.

COHN, Ruby. Sarah Kane, an Architect of Drama. cyc, Volume 18 n¹, mis en ligne le 17 juillet 2008. 
GARCIA, Cristina Delgado. Subversion, Refusal, and Contingency: The Transgression of LiberalHumanist Subjectivity and Characterization in Sarah Kane's Cleansed, Crave, and 4.48 Psychosis. Modern Drama, Volume 55, Number 2, Summer 2012, pp. 230-250

FISCHER-LICHTE. "Além da Interpretação" In: Ästhetische Erfahrung. Das Semiotische und das Performative. Tübingen: Francke, 2001, p. 219-231.

KANE, Sarah. Crave. 2000. Versão digital. Disponível em:

http:/ / pt.scribd.com/doc/38655660/Sarah-Kane-Crave

LEHMANN, Hans-Thies. Just a word on a Page and there is drama. Apontamentos sobre o texto no teatro pós-dramático. Tradução de Stephan Baumgärtel. Título original: "Just a word on a page and there is drama. Anmerkungen zum Text im postdramatischen Theater." In: Text und Kritik XI/04, ed. Heinz Ludwig Arnold, p. 26- 33.

PAME, Ousmane Aly. Sarah Kane's 'in-yer-face' theatrical paradigms. A study of Blasted (1995), Phaedra's Love (1996), Cleansed (1998), Crave(1998) and 4.48 Psychosis (2000). Disponível em:

http://www.fastef.ucad.sn/Lien10/liens10a5.pdf

PAMPLONA, Juliana. Um estudo sobre o personagem nas peças de Sarah Kane. Disponível em: http://www.seer.unirio.br/index.php/pesqcenicas/article/viewFile/735/694

POSCHMANN, Gerda. O texto teatral e o teatro fundamentado no texto. Tradução de Stephan Baumgärtel. Original em: Der nicht mehr dramatische Theatertext. Aktuelle Bühnenstücke und ihre dramaturgische Analyse. Tübingen: Niemeyer, 1997.

SAUNDERS, Graham. Love Me or Kill Me: Sarah Kane and the Theatre of Extremes. Manchester: Manchester University Press, 2002.

SERMON, Julie. O diálogo [segundo] enunciadores incertos. Tradução Stephan Baumgärtel e José Ronaldo Faleiro. Original em: "Le dialogue auxénonciateursincertains" em: Ryngaert, Jean-Pierre e tal. Nouveaux Territoires du Dialogue. ActesSudPapiers/CNSAD 2005, p.31-35.

URBAN, Ken. An ethics of catastrophe.The Theatre of Sarah Kane. PAJ: A Journal of Performance and Art 23.3 (2001) 36-46.

WARD, Ian. Rape and Rape Mythology in the Plays of Sarah Kane. Comparative Drama, Volume 47, Number 2, Summer 2013, pp. 225-248. 